\title{
OUTCOME OF USE OF HIGH QUALITY CHAMOMILE EXTRACT ON SLEEP DISORDERS OCCURRING AFTER MENOPAUSE
}

\author{
Ayesha Rasool ${ }^{1}$, Azka Ishtiaq ${ }^{2}$, Bareera Rehman $^{3}$ \\ 1,2,3. House Officer Nishtar Hospital, Multan \\ Correspounding Author:ayesharasool@gmail.com
}

\begin{abstract}
:
Objective: To compare the outcome of four weeks use of High Grade Extract of Chamomile and the placebo on sleep diary data. Study Design: Randomized controlled clinical trial. Place and Duration of Study: Gynecology outdoor, Nishtar Hospital Multan from January 22, 2018 to January 10, 2019. Methodology: Two equal groups were made with 53 menopausal women in each. Age, age at menarche and menopause, and BMI was compared between the two groups. Sleep latency, time and number of awakenings, total sleep time, sleep quality, sleep efficiency, PQSI score, BDI, FSS and STAI-T score were compared between both the groups at baseline and $28^{\text {th }}$ day. Student t-test was applied using SPSS v.23 computer software. P $>0.05$ was considered statistically insignificant._Results:_After 4 weeks of treatment, significant improvement was observed in sleep latency, time of waking after sleep onset, number of awakenings and total sleep time in the Chamomile group compared with placebo group $(0.023,0.002,0.019$ and $<0.001$, respectively). The improvement in STAI score was statistically significant (0.024) in the chamomile group. , There was some improvement observed in the chamomile group in terms of sleep quality (0.075) and sleep efficiency (0.059) but the differences were still statistically insignificant.

Conclusion: It is concluded that chamomile extract has significant beneficial effects on the menopausal women suffering from sleep disorders.
\end{abstract}

Keywords: menopause, sleep disorders, chamomile extract

DOI: $10.7176 / \mathrm{JMPB} / 52-12$

\section{Introduction:}

Menopause is an age related condition, experienced by all women. Menopause is term which describes those changes which a women undergoes just before or after the complete cessation of menstruation. This marks the end of reproductive age. When a female is born, there is a finite number of eggs present in the ovary. Hormones which are produced by the ovaries are estrogen and progesterone which play an important role in the regulation of ovulation and menstruation ${ }^{1}$. Menopause occurs when there are no more eggs present in the ovaries to be released and menstruation ceases. Normally, menopause occurs after the age of forty years. Earlier menopause also occurs, some causes of which are ovarian destruction following chemotherapy, hysterectomy, and premature ovarian syndrome and when occurring before the age of forty years, it is termed as premature menopause ${ }^{2}$. As the age of menopause approaches, most common symptoms experienced by the women are hot flushes, mood swings, fatigue, depression, insomnia, irritability and joint and muscle aches ${ }^{3,4,5}$.

Many sleep related complaints are associated with menopause. In spite of extensive symptoms, few polysomnographic changes have been documented which are associated with menopause. There were no significant changes observed in the polysomnograms when the individuals, who were transitioning to menopause, were surveyed with polysomnography in the Wisconsin cohort ${ }^{6}$, rather an increase in obstructive sleep apnea was 
observed. Similar pattern s observed in the polysomnograms of young men and women, but increasing age, women incline to maintain delta sleep pattern for a longer time as compared the young men. There is worsening of sleep efficiency in older menopausal women as compared with the young ovulating women ${ }^{7,8}$. Vasomotor instability is the chief problem of menopause in a subset of women which ultimately results in disturbance of sleep. This sleep disturbance is nor experience by all the menopausal women.

One of the most ancient herbs known to mankind is chamomile. Two varieties are known, German chamomile and Roman chamomile. A variety of flavonoids and terpenoids are found in the dried leaves of chamomile, due to which $t$ is vastly used in the preparation of medicines. Chamomile is commonly used in the form of tea. Most common therapeutic uses of chamomile include menstrual irregularities, insomnia, inflammation, hemorrhoids, muscle spasms, ulcers and gastrointestinal disorders. Essential oils present in chamomile are an important component in cosmetic as well as aromatherapy. Morin et al. ${ }^{9}$ observed that almost $15 \%$ of the adults use some sort of herbal remedies for their sleep disorders compared with $11 \%$ who were using prescription medication. Sedative effect of chamomile is thought to be caused by apigenin, a flavonoid constituent of chamomile, through modification of Gama aminobutyric acid (GABA) receptors ${ }^{10}$. In the study by Kupfersztain et al. ${ }^{11}$ observed that there was a significant alleviation of fatigue and sleep disturbances by twelve weeks use of herbal extract of chamomile. Kakuta $\mathrm{H}$ et al. ${ }^{12}$ revealed that the patients receiving chamomile jelly experienced more relaxation. Sleep diaries of young men showed lesser latency in onset of sleep, night time awakenings and morning sleepiness. Some studies have been conducted to observe the efficacy of use of chamomile extract in improving the sleep disorders and day time functioning capabilities in general population but the data is still lacking. We steered current study to detect the effectiveness of four weeks use of high quality chamomile extract in removing the complaints of sleep disturbances by the post-menopausal women when compared with the patents who received placebo.

\section{Material and methodology:}

We selected 106 post-menopausal women who presented to the Gynecology outdoor patients department at Nishtar Hospital Multan, with any type of sleep disturbance over a time period from January 22, 2018 to January 10, 2019. Sample size was calculated by taking the study by Zick SM et al. ${ }^{13}$ as reference. Ethical approval was obtained from the ethics committee of the respective hospital. All the patients who gave past history of congestive heart failure, cancer, asthma, mood or anxiety disorder, obsessive compulsive disorder, lifelong psychotic or bipolar disorder, obstructive sleep apnea, substance abuse disorder, restless leg syndrome and known allergy to chamomile or other members of ragweed family, were excluded from this study.

All the patients were explained about the complete procedure and informed consent on written forms was obtained. Age of patients, age at menarche and menopause, and body mass index of all the patients was recorded. All the patients were asked to complete their sleep diaries on every morning for one whole week prior to the start of the trial. After that, all the patients were randomly divided into two groups, one group to receive 30 oral drops mixed $50 \mathrm{ml}$ of water of high grade extract of chamomile (Plant Therapy German Chamomile), twice daily and the other group to receive corresponding dose of the placebo. All the patients were advised to take their medicine, first dose after lunch and the second dose one hour before going to bed. Patients were also advised to fill their sleep diaries during the fourth week of their treatment. All the patients were called back in the outdoor clinic on the $28^{\text {th }}$ day. In the sleep diary, patients were to record bed time, wake up time, latency in sleep onset, time of awakening after 
the sleep onset, number of awakenings after sleep onset and the quality of sleep. Primary variables which were derived from the sleep diary were sleep efficiency (total sleep time / time in bed $\times 100$ ) and Total sleep time. Secondary variables recoded were the common consequence of sleeplessness over day time functioning. For that purpose, patients were requested to complete their Beck Depression Inventory (BDI) ${ }^{14}$, Fatigue Severity Scale ${ }^{15}$ and State Trait Anxiety Inventory Trait Subscale (STAI-T) ${ }^{16}$ along with Pittsburgh Sleep Quality Index (PSQI)

17 , on the baseline visit as well as the $28^{\text {th }}$ day visit.

Age, age at menarche and menopause, and body mass index was compared between the two groups. Sleep latency, time of awakening after sleep, number of awakenings, total sleep time, sleep quality, sleep efficiency, Pittsburgh Sleep Quality Index total score, Beck Depression Inventory (BDI), Fatigue Severity Scale (FSS) and State Trait Anxiety Inventory Trait Subscale (STAI-T) were compared between both the groups both before and after four weeks trial with high quality extract of chamomile and corresponding placebo. As all the data was continuous, so Student t-test was applied using SPSS v.23 computer software. P value above 0.05 was considered statistically insignificant.

\section{Results:}

We selected one hundred and six menopausal women and assorted them randomly into two groups with same number of patients. When matched, both the groups were not significantly different considering the mean age of patients, mean age of menarche of patients, mean age of menopause and mean body mass index ( $\mathrm{p}$ value 0.074 , $0.527,0.331$ and 0.133 , respectively). Table-I

Prior to the start of treatment, sleep latency, time of waking after the onset of sleep, number of awakenings and total sleep time were not significantly different ( $\mathrm{p}$ value $0.536,0.339,0.254$, and 0.614 , respectively). When the treatment was continued for at least four weeks and data was recorded again, a significant improvement was observed in sleep latency, time of waking after the onset of sleep, number of awakenings and total sleep time in the Chamomile group when compared with placebo group ( $\mathrm{p}$ value $0.023,0.002,0.019$ and $<0.001$, respectively). Before the treatment, there was no significant difference in the data of sleep quality $(p=0.187)$, sleep efficiency $(p=0.185)$ and PQSI total score $(p=0.243)$ between the chamomile and the placebo groups. After a full four weeks treatment, there was some improvement observed in the chamomile group in terms of sleep quality $(\mathrm{p}=$ $0.075)$ and sleep efficiency $(p=0.059)$ but the difference was still statistically insignificant. There was no significant difference in the improvement of PQSI total score by the $4^{\text {th }}$ week of treatment $(\mathrm{p}=0.675)$. Table-II

When the data about the day time functioning was recorded prior to the start of the treatment, the difference in fatigue severity scale score and State trait anxiety inventory score was of no statistical significance ( $\mathrm{p}$ value 0.468 and 0.465, respectively) but the difference in Beck depression inventory score was significant ( $\mathrm{p}$ value 0.047). After the completion of four week treatment, no significantly different improvement was observed in the chamomile group in comparison with the placebo group in terms of fatigue severity scale score ( $p$ value 0.242 ) and Beck depression inventory ( $p$ value 0.067 ) but the improvement in State trait anxiety inventory score was statistically significant ( $\mathrm{p}$ value 0.024 ) in the chamomile group. Table-III 


\section{Table-I}

Baseline Characteristics

\begin{tabular}{|l|c|c|c|}
\hline \multicolumn{1}{|c|}{ Variable } & Placebo $(\mathbf{n}=\mathbf{5 3})$ & Chamomile $(\mathbf{n}=\mathbf{5 3})$ & p-value \\
\hline Age, years & $49.66 \pm 3.92$ & $51.09 \pm 4.25$ & 0.074 \\
\hline Age at menopause, years & $49.79 \pm 2.52$ & $49.32 \pm 2.45$ & 0.331 \\
\hline Age at menarche, years & $13.77 \pm 1.34$ & $13.62 \pm 1.09$ & 0.527 \\
\hline Body mass index, $\mathrm{kg} / \mathrm{m}^{2}$ & $28.07 \pm 4.03$ & $29.21 \pm 3.66$ & 0.133 \\
\hline
\end{tabular}

Data is entered as Mean \pm S.D

\section{Table-II}

Sleep Diary Data by the Patients

\begin{tabular}{|c|c|c|c|c|}
\hline Variable & Time frame & $\begin{array}{c}\text { Placebo- Group } \\
\qquad(\mathrm{n}=53)\end{array}$ & $\begin{array}{l}\text { Chamomile- } \\
\text { Group }(n=53)\end{array}$ & p-value \\
\hline \multirow[t]{2}{*}{ Sleep Latency, min } & Baseline & $42.38 \pm 17.72$ & $40.38 \pm 15.35$ & 0.536 \\
\hline & $4^{\text {th }}$ Week & $28.49 \pm 10.62$ & $24.49 \pm 6.85$ & 0.023 \\
\hline \multirow[t]{2}{*}{ Wake after sleep Onset, min } & Baseline & $37.94 \pm 18.39$ & $41.28 \pm 17.43$ & 0.339 \\
\hline & $4^{\text {th }}$ Week & $37.58 \pm 8.62$ & $31.87 \pm 9.47$ & 0.002 \\
\hline \multirow[t]{2}{*}{ Awakenings (number) } & Baseline & $1.77 \pm 1.01$ & $1.57 \pm 0.84$ & 0.254 \\
\hline & $4^{\text {th }}$ Week & $1.49 \pm 0.72$ & $1.15 \pm 0.72$ & 0.019 \\
\hline \multirow[t]{2}{*}{ Total sleep time, hours } & Baseline & $5.26 \pm 1.43$ & $5.39 \pm 1.17$ & 0.614 \\
\hline & $4^{\text {th }}$ Week & $5.28 \pm 1.09$ & $6.47 \pm 1.01$ & $<0.001$ \\
\hline \multirow[t]{2}{*}{ Sleep Efficiency (\%) } & Baseline & $75.51 \pm 6.92$ & $77.23 \pm 6.31$ & 0.185 \\
\hline & $4^{\text {th }}$ Week & $78.58 \pm 6.52$ & $80.89 \pm 5.85$ & 0.059 \\
\hline \multirow[t]{2}{*}{ PQSI Total Score } & Baseline & $9.60 \pm 2.06$ & $10.13 \pm 2.54$ & 0.243 \\
\hline & $4^{\text {th }}$ Week & $5.96 \pm 1.44$ & $6.07 \pm 1.33$ & 0.675 \\
\hline
\end{tabular}

Data is entered as Mean \pm S.D; PQSI $=$ Pittsburgh Sleep Quality Index

\section{Table-III}

Day Time Functioning Data by the Patients

\begin{tabular}{|c|c|c|c|c|}
\hline Variable & Time frame & $\begin{array}{l}\text { Placebo- Group } \\
\qquad(\mathrm{n}=53)\end{array}$ & $\begin{array}{l}\text { Chamomile- } \\
\text { Group }(n=53)\end{array}$ & p-value \\
\hline \multirow[t]{2}{*}{ FSS } & Baseline & $30.81 \pm 12.64$ & $32.42 \pm 9.84$ & 0.468 \\
\hline & $4^{\text {th }}$ Week & $26.68 \pm 9.74$ & $24.92 \pm 4.80$ & 0.242 \\
\hline \multirow[t]{2}{*}{ BDI } & Baseline & $9.91 \pm 3.24$ & $8.62 \pm 3.34$ & 0.047 \\
\hline & $4^{\text {th }}$ Week & $8.94 \pm 3.38$ & $7.79 \pm 3.01$ & 0.067 \\
\hline \multirow[t]{2}{*}{ STAI Trait Subscale } & Baseline & $34.15 \pm 9.35$ & $35.45 \pm 8.92$ & 0.465 \\
\hline & $4^{\text {th }}$ Week & $29.06 \pm 7.12$ & $26.17 \pm 5.74$ & 0.024 \\
\hline
\end{tabular}

Data is entered as Mean \pm S.D; FSS=Fatigue severity scale; BDI= Beck depression inventory; STAI= State trait anxiety inventory 


\section{Discussion:}

In our study we observed that there was a significant improvement in latency of sleep onset, number and duration of awakenings after sleep onset and total sleep time after four week use of high quality extract of chamomile. There was also betterment in day time performance as there was significant improvement observed in the State trait anxiety inventory subscale score. Although no statistically significant, an improvement in sleep quality as well as sleep efficiency was observed. Similar results were observed in the study conducted by Zick SM et al. ${ }^{13}$ on the patients suffering from insomnia. In their study, there was significant improvement in sleep efficiency, total sleep time, sleep latency, fatigue severity scale score and state trait anxiety inventory subscale score.

With the increasing age, there is deterioration in the sleep quality and increase in the sleep disturbances in the menopausal women in comparison with young ovulating women ${ }^{7,8}$. In a different study, a significant worsening of sleep continuity was seen in the women of the age range between forty six to fifty two years ${ }^{18}$. There is an increase in the occurrence of sleep disorders in the women who are in the transition phase of menopause ${ }^{19}$. These aberrations in the sleep patterns can be really problematic for some women and day time performance may be influenced in a negative way. These all events, in long term, tend to affect the physical as well as mental health of women ${ }^{19}$. There can be really beneficial effects of chamomile extract usage in such patients. As shown in the study by Kakuta $\mathrm{H}$ et al. ${ }^{12}$, the patients who were taking chamomile jelly experienced additional relaxation. Sleep diaries of young males disclosed reduced latency in onset of sleep, night time awakenings and early morning sleepiness. Chang SM et al. ${ }^{20}$ studied the effects of chamomile tea on the postpartum women who were having sleep difficulties. They concluded that it is useful to recommend chamomile tea to the postpartum women as a supplement and it can significantly lessen the problems related to quality of sleep and depression. Still there is need to conduct more studies to clearly define the effects of chamomile on sleep abnormalities in the menopausal women.

\section{Conclusion:}

It is concluded that chamomile extract has significant beneficial effects on the menopausal women suffering from sleep disorders. Chamomile extract is related with no observable side effects when used for a short period of time but has greater positive effects on sleep quality and efficiency.

\section{Conflict of interest:}

No conflict of interest regarding this study.

\section{Funding Source:}

No external funding sources used.

\section{References:}

1. Santoro N, et al. Menstrual Cycle Hormone Changes in Women Traversing Menopause: Study of Women's Health Across the Nation. J Clin Endocrinol Metabol. 2017;102(7):2218-29.

2. Scott EL, Zhang QG, Vadlamudi RK, Brann DW. Premature menopause and risk of neurological disease: basic mechanisms and clinical implications. Mol Cell Endocrinol. 2014;389(1-2):2-6.

3. Eichling PS, Sahni J. Menopause related sleep disorders. J Clin Sleep Med. 2005;1(03):291-300. 
4. Monteleone P, Mascagni G, Giannini A, Genazzani AR, Simoncini T. Symptoms of menopause-global prevalence, physiology and implications. Nat Rev Endocrinol. 2018.

5. Ameratunga D, Goldin J, Hickey M. Sleep disturbance in menopause. Intern Med J. 2012;42(7):742-7.

6. Young T, Rabago D, Zgierska A, Austin D, Finn L. Objective and subjective sleep quality in premenopausal, perimenopausal, and postmenopausal women in the Wisconsin Sleep Cohort Study. Sleep. 2003;26(6):667-72.

7. Shaver JL, Woods NF. Sleep and menopause: a narrative review. Menopause. 2015;22(8):899-915.

8. Freeman EW, Sammel MD, Gross SA, Pien GW. Poor sleep in relation to natural menopause: a populationbased 14-year follow-up of mid-life women. Menopause (New York, NY). 2015;22(7):719.

9. Morin CM, LeBlanc M, Daley M, Gregoire JP, Merette C. Epidemiology of insomnia: prevalence, self-help treatments, consultations, and determinants of help-seeking behaviors. Sleep Med. 2006;7(2):123-30.

10. Campbell EL, Chebib M, Johnston GA. The dietary flavonoids apigenin and (-)-epigallocatechin gallate enhance the positive modulation by diazepam of the activation by GABA of recombinant GABAA receptors. Biochem Pharmacol. 2004;68(8):1631-8.

11. Kupfersztain C, Rotem C, Fagot R, Kaplan B. The immediate effect of natural plant extract, Angelica sinensis and Matricaria chamomilla (Climex) for the treatment of hot flushes during menopause. A preliminary report. Clin Exp Obstet Gynecol. 2003;30(4):203-6.

12. Kakuta H, Yano-Kakuta E, Moriya K. Psychological and Physiological Effects in Humans of Eating Chamomile Jelly. ACTA HORTIC, 2006(pp. 187-192).

13. Zick SM, Wright BD, Sen A, Arnedt JT. Preliminary examination of the efficacy and safety of a standardized chamomile extract for chronic primary insomnia: a randomized placebo-controlled pilot study. BMC Complement Altern Med. 2011;11(1):78.

14. Beck AT, Steer RA, Brown GK. Beck depression inventory-II. San Antonio. 1996;78(2):490-8.

15. Krupp LB, LaRocca NG, Muir-Nash J, Steinberg AD. The fatigue severity scale: application to patients with multiple sclerosis and systemic lupus erythematosus. Arch Neurol. 1989;46(10):1121-3.

16. Spielberger CD. State-Trait anxiety inventory. John Wiley \& Sons, Inc.; 2010.

17. Backhaus J, Junghanns K, Broocks A, Riemann D, Hohagen F. Test-retest reliability and validity of the Pittsburgh Sleep Quality Index in primary insomnia. J Psychosom Res. 2002;53(3):737-40.

18. Lampio L, Polo-Kantola P, Himanen SL, Kurki S, Huupponen E, Engblom J, Heinonen OJ, Polo O, Saaresranta T. Sleep During Menopausal Transition: A 6-Year Follow-Up. Sleep. 2017;40(7).

19. Baker FC, de Zambotti M, Colrain IM, Bei B. Sleep problems during the menopausal transition: prevalence, impact, and management challenges. Nat Sci Sleep. 2018;10:73.

20. Chang SM, Chen $\mathrm{CH}$. Effects of an intervention with drinking chamomile tea on sleep quality and depression in sleep disturbed postnatal women: a randomized controlled trial. J Adv Nurs. 2016;72(2):30615. 